\title{
水电站运行管理存在的问题及解决策略
}

张欢

新疆伊犁河流域开发建设管理局

DOI:10.32629/hwr.v3i6.2187

[摘 要] 随着我国经济的不断发展, 对自然资源、新能源的需求也不断增大。电负荷需求的加剧, 对水电站的运行给予了巨大 的压力。水电站同属工业消耗, 不断运行的状态下, 设备的老化、环境的变化、人力成本的增加等等都给水电站的发展带来了 一定的影响。因此实际运行管理中,应当基于双效理念而开展工作,在保证用电稳定、安全的前提下充分发挥水电站的作用, 同时可实现水电站的经济效益更大化。本文主要分析当前某些较为偏远地区的中小型水电站运行管理中存在的问题,对此提 出优化策略, 可供一定参考。

[关键词] 水电站; 运行管理; 优化措施

随着我国对新能源的需求越来越大, 水电站的建设规模 随之增多, 其产出效益可谓空前。经济稍发达地区由于对水 电站的要求较为严格, 其运行体系、管理模式得到了先进技 术、理念的融入, 尚且不存在明显的问题漏洞。而大部分水 电站处于地理较为偏远的位置, 其资源分配、管理架构、技 术支持等等皆不均衡, 管理力度相对来说家较为松散, 而同 时由于地质环境的多变性, 给水电站的运行管理带来诸多风 险与问题。水电站作为当前最为重要的发展项目之一, 其安 全、稳定的运行是前提, 其次才是高效性要求。因此, 首先应 当从水电站实际问题与需求出发, 对此进行科学、系统性、切 实的分析, 对其采取针对性、切实性的优化策略, 从没有问题 到试验问题、挖掘问题, 再到逐步的完善优化, 促进水电事业 的高层次发展。

\section{1 当前水电站运行管理中现状及存在问题}

1. 1 工作人员整体水平有待提升

随着各项高新技术、设备的融入, 对技术人才提出了更 高的要求。电力企业对技术管理的重视程度越发增多, 技术 人员在水电站运行管理中的位置也位列前端。技术人员不仅 要保证整个水电站的稳定运行, 还要时刻监控水电站运行中 发生的问题与潜在性漏洞, 实施维护与检修以及设备的常规 管理。由于大部分水电站地理位置较偏远, 其技术设备、资 源分配等等都得不到良好的支持, 相关专业技术人员即较 少。主要问题在于:

1.1.1 水电站的初期使用时, 水电站运行管理的工作人 员其综合技能、素质不均衡, 且大部分偏低, 而部分工作人员 并不具有相关的专业技能, 设备的运行与维护、检修方面缺 乏资源。

1.1.2由于地处偏远, 人力分配模式往往不完善, 企业缺 乏对运行管理、技术人才的培训, 无法切实满足水电站的实 际需求, 以直接造成水电站运行管理中存在的各项问题。

1. 2 工作安全细节意识的缺乏

符合水电站实际需求与发展的规则制度是前提。由于水 电站客观存在的影响因素以及工作人员主观意义上的思想
问题, 水电站的安全运行细节意识较为残缺。一方面, 部分维 护人员的工作态度存在问题, 其随意性较大, 对两票三制原 则的重视程度较差, 违规工作现象时常存在, 而同时约束机 制的不完善, 加剧了问题存在的严重性以及生产工作的安全 隐患 ${ }^{[1]}$ 。另一方面, 仍旧是两票三制的落实问题, 值班人员的 巡检工作不到位, 其工作态度与工作意识较差, 通常随意 “晃” 几圈以应付任务, 对设备未进行实质性的考察、检查、 分析, 侧面来说即是忽略了潜在性问题, 间接影响了设备的 安全运行。例如: 机组水头测值存在误差与拦污栅轻微堵塞 等问题, 对水轮发电机组运行性能造成影响, 而由于涉及水 工、或设备的不足等原因, 无法进行针对性的解决方案, 导致 机组无法正常运行, 甚至安全事故的发生, 运行水电站的工 作质量。

\section{3 安全事故缺乏应急处理能力}

水电站的日常运行中, 由于地理环境的多变, 可能对设 备造成一定的影响, 继而出现故障问题, 那么这就需要技术 人员及时解决问题的应急管理能力, 将损耗降低至最低范围 内。所以, 及时性是主要问题。一方面是由于水电站的运行 体系不完善, 首先是缺乏优质的技术人才, 与巡检人员的问 题挖掘能力, 导致安全事故的突然发生而无法快速的分析问 题、解决问题, 错失解决的最佳时期, 继而直接影响设备的使 用寿命与后续运行情况。一方面是水电站的维护、升级问题, 受到周边环境的影响, 水电站应定期进行检查以及升级。

1.4 设备检修管理机制不完善

水电站设备检查得到有效保障的前提, 是完整的管理机 制。技术人员进行巡检时, 按照相应的检查机制, 对设备的实 际运行情况与参数变化进行检查, 尽力挖掘潜在性的问题, 避免设备的故障发生。对每一次检查、存在问题进行详细的 记录, 同步至水电站档案管理, 并上传至站点总控中心, 供管 理人员分析、指导。但由于部分工作人员综合素质问题, 对 设备未进行认真的检查与记录, 导致设备潜在性问题被放大, 设备故障的发生。

2 优化水电站运行管理质量的策略分析 


\section{1 不断强化工作人员培训工作}

水电站的日常运行管理的提高, 前提是管理人员达到一 定标准。为了根据社会发展、适应水电站发展的实际需求, 即首先应当强化对管理人员的再培训, 不断提高其职业素 养、综合素质、运行管理思想与水平 ${ }^{[2]}$ 。具体包括以下:

2. 1.1 企业高层应基于水电站的实际发展情况与发展需 求, 建立对应的人才培养机制, 促使管理体系的科学合理性、 标准一体化。对工作人员的培训, 可充分提高其积极性与忠 诚感、归属感, 全面提升水电站工作人员的职业素养、管理 能力。

2. 1. 2技术是根本, 综合素质是辅助。在提升技术人员能 力的同时, 还应重视其综合素质的培养。对其职业发展目标、 职业心理进行适当的培养, 提高其工作认同感、清晰的自我 定位, 有助于工作效率、质量的提高。

2.1.3 通过对管理体系的不断优化, 切实提高技术人员 水平。企业发展之本是员工, 员工的工作之本是薪酬与自我 价值实现。在确保其基本薪酬的基础上, 开展对应的福利机 制, 激发其工作积极性, 更有效的服务于水电站, 促进水电站 的安全、稳定发展。

\section{2 安全意识的培训是基础}

安全意识的教育培训中, 应具有一定程度的多元化。例 如, 对日常值班人员进行 《电气操作导则》的讲解与分析。 保证其工作的规范性、避免安全事故的发生。同时, 应结合 实际案例教学, 可让工作人员进行分析, 提高其问题挖掘、判 断分析能力, 有助于安全意识与巡检水平的提高, 保证两票 三制的有效落实 ${ }^{[3]}$ 。此外, 对于部分工作人员对技术培训的 重视程度不够、积极性不高的现象, 应对进行一定的约束, 可进行相关考核, 使其认识到自身不足, 提高其技术培训的 重视程度。实际开展中, 除了实际案例的讲解, 还可邀请厂家 技术人员或专家到场进行实地讲解, 对设备的现场管理、维 护、检修等等进行对应的培训。跟紧时代发展, 可建立工作 人员交流平台, 可建立微信交流群, 增强员工的互动性。一方 面可共享自身技术经验供大家参考、分析以达到再次优化, 一方面可方便安全事故的应急处理, 现场连线增强时效性。

\section{3加强设备维护水平的管理}

水电行业相关规定, 水电建筑以及机电设备的检修与升 级主要包括日常操作与年度深度检修两种 ${ }^{[4]}$ 。年度深度检修 一般在冬季枯水期来临之前, 日常维修则是检修人员的日常 管理工作。进行年度深度检修之前, 首先必须分析设备一年 以来的运行情况、发生问题以及日常检修记录, 针对问题存 在进行针对性的项目检修。设备的检修主要包括对机电主要
设备、辅助设备的运行性能测试, 进行维护保养或更换部件 升级。为确保检修的实质性、有效性，首先基于 “预防为首、 质量顶级、安全第一” 的原则, 检修现场必须配备上级单位 或第三方监督人员, “遵循需修必修, 要修必修好” 的工作准 则, 严格控制现场检修工作, 保证设备维护的有效性。

\section{4加强技术人员工作情况的管理}

技术管理是基础, 是重点。应培养技术人员主动学习对 机电设备的检修判断分析能力、出现问题的及时性解决能 力。单位首先需认真考察水电站工作人员工作情况, 进行相 应的专业技术培训活动, 对每种机电设备必须达到 “闭眼可 认清”-—以确保某些极端条件下依然可进行设备的抢修。 培训活动, 每年应当根据日常检修记录情况而针对性的开展, 不可盲目为了培训而培训, 杜绝单位资源的浪费以及影响工 作人员心态。同时，应当制定约束机制以及落实责任主体制。 技术人员日常工作中, 可对其安装操作监控系统, 对其进行 设备检修、维护落实情况的监督与引导。约束机制与责任主 体制, 予以工作人员一定的压力, 同时可增强其职业认同感。 双向监督与培养, 切实提高工作效率与质量, 促进水电站的 全面发展。

\section{3 结语}

虽然我国工业体系在世界上身居高位, 各项技术都已经 得到了升级优化, 但尚未覆盖到所有地区, 部分经济尚不发 达的地区仍旧存在各项问题。在对水电站进行改善优化的过 程中, 必须从水电站的资源更有效使用的角度出发, 对其制 定针对性的改善策略与发展方针, 不断提高水电站运行质量 的同时, 还应连带到整个水电行业的健康发展。基于水电站 安全、稳定、高效、经济性的发展原则, 迎合高新技术的融 入, 加大相关技术的人才培养、开发, 优化运行管理体系, 切 实保证运维和一。应是管理促进不断发展, 而不是发展带动 了管理效率的提升, 管理承建起发展, 发展补充了管理, 充分 发挥水电站的职能作用, 为社会经济的发展贡献其所有力量。

\section{[参考文献]}

[1]䣏奎. 对中小水电站运行管理的建议及对策[J].工程 建设与设计,2018,(21):264-265+268。

[2]王虎心.小型水电站稳定运行管控措施的研究[J].智 能城市,2018,4(17):124-125.

[3] 秦沛源.水电站运行管理存在的问题及解决策略 [J]. 低碳世界,2018,(08):158-159.

[4]颜琳,潘种.中小型水电站运行管理存在的问题及对 策[J].设备管理与维修,2018,(10):18-20. 